\title{
Ricardo WAVE Simulation on the Effect of Exhaust Header Geometry to the Power and Torque of the UGM's FSAE Engine
}

\author{
Fauzun $^{1}$, Arif Kurniawan ${ }^{2}$ \\ Department of Mechanical and Industrial Engineering, Faculty of Engineering, \\ Universitas Gadjah Mada, Jl. Grafika No. 2, Yogyakarta 55281, Indonesia \\ ${ }^{1}$ fauzun71@ugm.ac.id \\ 2 arif.kurniawan21@mail.ugm.ac.id
}

\begin{abstract}
Header is a component inside an exhaust system which delivers the exhaust gas flow produced by engine combustion process. UGM's FSAE car Bimasakti, which took part in a racing competition, needs components with excellent performance including the header component. The present study is aimed at obtaining the geometry of the header exhaust system that can optimize the power and torque of the engine KTM 450 SX-F while still complying with the Student Formula SAE competition's regulations. This research used an engine and one-dimensional gas dynamics simulation software known as the Ricardo WAVE. This software was used to simulate the powertrain system model of the 5th generation Bimasakti. From the initial model, changes towards the header geometry with variations in diameters and pipe lengths were conducted. After the best design has been obtained, developments towards at the above-mentioned design with additions of expansion chamber, stepped pipe, and diffuser shapes were then conducted. The obtained results showed that larger diameter of header can produce the better power and torque value at both low and high RPMs, whereas smaller diameter size would produce a better power and torque value at medium RPM. The effect of the use of longer header length can produce a better power and torque value at medium RPM, while shorter length would produce a better power and torque value at high RPM. Also, it is obtained that the addition of expansion chamber shape will reduce the engine's power and torque, while the addition of stepped pipe and diffuser shapes will increase the power and torque value at high RPM.
\end{abstract}

Keyword-Header, Exhaust System, Ricardo WAVE, FSAE

\section{INTRODUCTION}

The automotive world is always bustling with enthusiasts and constantly developing in terms of performance and standards. Advancement in the automotive industry is also driven by a variety of sports competitions such as Formula, Rally, Moto GP, Motocross, and others. Formula car racing is a competition that is currently the pinnacle of the automotive world research. There are various classes of formula cars, one of which is student formula SAE a competition designed for students from all universities across the world. The formula student competition organized by the parent organization of the automotive world is the Society of Automotive Engineers (SAE) and must comply with the regulations [1].

Engine is one of the most critical components in a vehicle. This component produces power that is then transmitted to the drivetrain system to spin the wheel. In racing competition, the performance generated by the engine must be maximized. However, the effort to maximize engine performance often clash with the rules of the competition. Therefore, various research and experiments are conducted in order to generate optimum engine performance while maintaining compliance with the current regulations.

Although combustion in the cylinder is the factor that affects engine performance the most, the design of intake system and exhaust system piping has been widely recognized as an important factor to note [3]. The gas flow processes into, though, and out of an engine are all unsteady. Unsteady gas flow is defined as that in which the pressure, temperature, and gas particle velocity in a duct are variable over time. In the case of induction flow into the cylinder through an intake valve whose area changes over time, the intake pipe pressure changes because the cylinder pressure is affected by the piston motion causing volumetric change within that space. In the case of exhaust flow, unsteady gas flow behavior is produced because the cylinder pressure falls with the rapid opening of the exhaust valve or valves. This gives the exhaust pipe a pressure that changes over time [2]. This issue is behind the inception of many industrial of intake and exhaust systems that offer various advantages in terms of performance, noise, appearance and others.

Because the performance characteristics of an engine are significantly controlled by this unsteady gas motion, it behooves the designer of engines to understand this flow mechanism thoroughly [2]. Various studies on the exhaust system [3] - [13] have been conducted by varying the geometry of the header, and of course with various methods and parameters being used. Research about exhaust system that is specifically made for the 
Formula SAE has also been done [10] - [13]. Therefore, through this research, it is expected to produce an exhaust header according to the needs of the Bimasakti UGM car that uses the KTM 450 SX-F engine.

\section{Methods}

In this research, the powertrain system of the Formula SAE Bimasakti car is used for the simulation. The design of the Bimasakti race car is shown in Fig. 1. The powertrain system model is made using Ricardo WAVE software. The intake system is made up of the bell mouth, throttle body, restrictor, plenum, and intake manifold. The engine is made up of the intake port, cylinder, exhaust port, and the exhaust system is made up of the adaptor, header, muffler, and tail pipe.

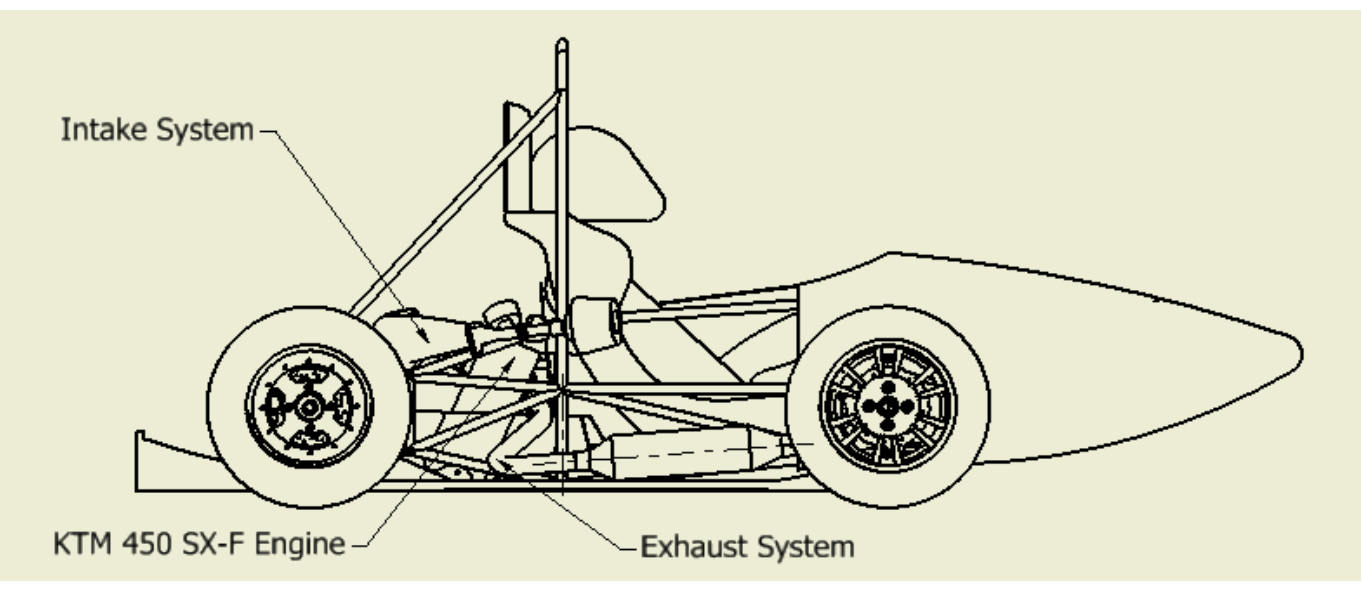

Fig. 1. Design of the $5^{\text {th }}$ generation Bimasakti FSAE car

\section{A. Data Collection}

Each powertrain system component is modelled according to the existing dimension. The data of the dimension and specification of the KTM 450 SX-F engine is shown in Table I.

TABLE I Data of the Dimension and Specification of the KTM 450 SX-F Engine

\begin{tabular}{|l|l|}
\hline Data & Value \\
\hline Number of cylinder & Single cylinder \\
\hline Cycle & 4 Stroke \\
\hline Bore & $95.0 \mathrm{~mm}$ \\
\hline Stroke & $63.4 \mathrm{~mm}$ \\
\hline TDC clearance & $1.02 \mathrm{~mm}$ \\
\hline Combustion chamber area & $7,478 \mathrm{~mm}^{2}$ \\
\hline Piston crown area & $7,450 \mathrm{~mm}^{2}$ \\
\hline Connecting rod length & $114 \mathrm{~mm}$ \\
\hline Wrist pin offset & 0 \\
\hline Compression ratio & 12.6 \\
\hline Number of valve & 4 \\
\hline Intake valve seat diameter & $34 \mathrm{~mm}$ \\
\hline Intake valve lash & $0.15 \mathrm{~mm}$ \\
\hline Intake valve maximum lift & $10.375 \mathrm{~mm} @ 460^{\circ}$ \\
\hline IVO - IVC & $320^{\circ}-620^{\circ}$ \\
\hline Exhaust valve seat diameter & $29 \mathrm{~mm}$ \\
\hline Exhaust valve lash & $0.17 \mathrm{~mm}$ \\
\hline Exhaust valve maximum lift & $8.705 \mathrm{~mm} @ 220^{\circ}$ \\
\hline EVO - EVC & $60^{\circ}-360^{\circ}$ \\
\hline Working engine speed & $3,000-10,000 \mathrm{rpm}$ \\
\hline
\end{tabular}

Aside from the dimension data, here need other parameters there are the pressure, ambient temperature, working fluid, as well as the wall temperature data on all powertrain system are in idle condition or 3,000 rpm. For the purpose of the assessment, the measurement would be done on an engine test bed, as shown in Fig. 2. 


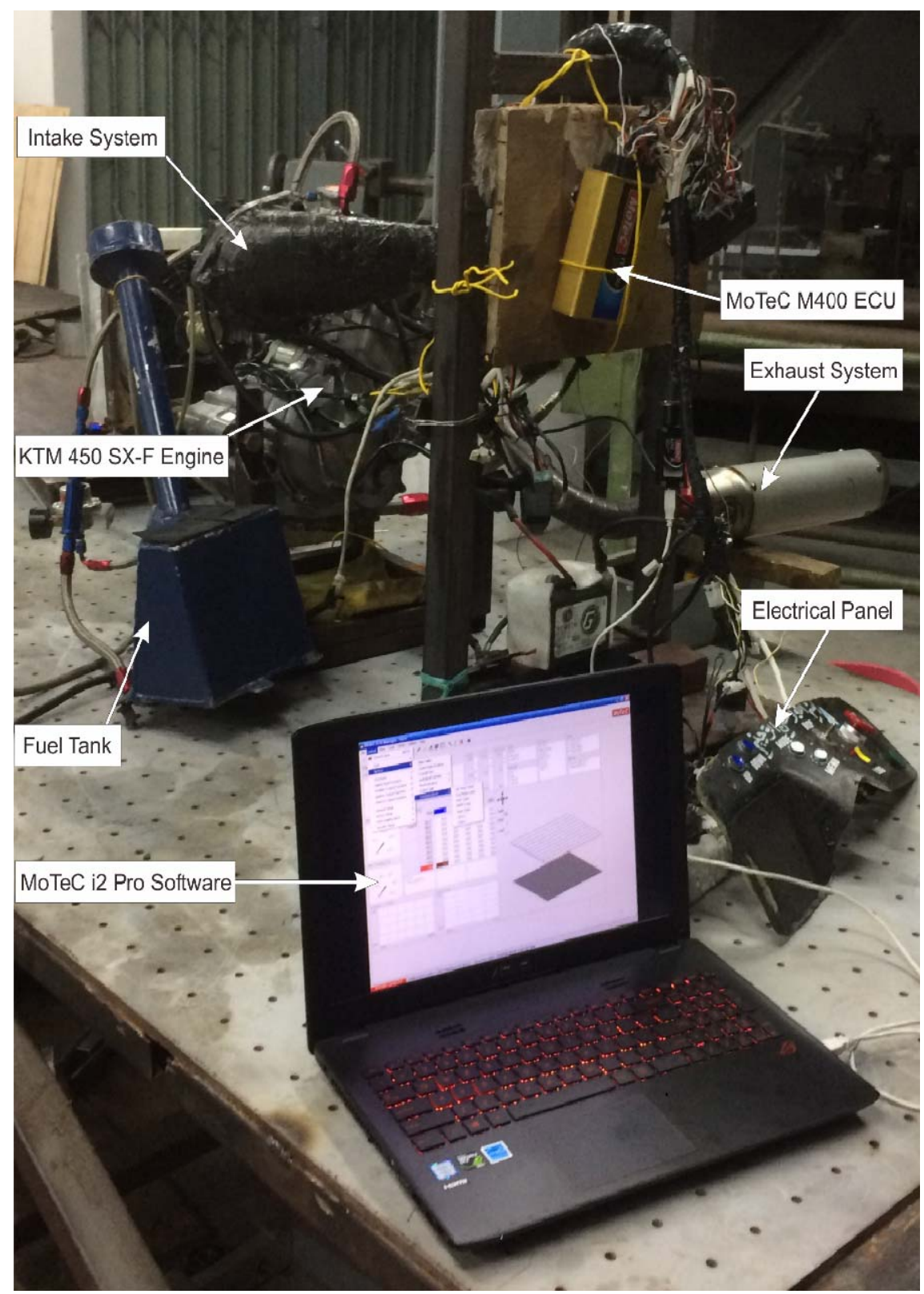

Fig. 2. Engine test bed

The pressure and ambient temperature data is gathered from the measurement by the sensors found on the throttle body. The pressure of the intake system is measured by the Delco 1 bar manifold absolute pressure sensor, while the exhaust system is measured using the VDO 10 bar gas pressure sensor. The sensor result is read by the ECU MoTeC M400 so that the result can be seen using the MoTeC i2 Pro software. The fluid temperature on the intake system and the exhaust system is measured using the thermocouple type-K sensor, and the result could be seen real-time using the Krisbow KW08-278 thermometer. Table II shows the data of the results.

TABLE II Ambient and Working Fluid Data of the Pressure and Temperature

\begin{tabular}{|l|l|l|}
\hline Section & Pressure & Temperature \\
\hline Ambient & $0.99 \mathrm{bar}$ & $304 \mathrm{~K}$ \\
\hline Intake System & $0.46 \mathrm{bar}$ & $307 \mathrm{~K}$ \\
\hline Exhaust System & $1.09 \mathrm{bar}$ & $1157 \mathrm{~K}$ \\
\hline
\end{tabular}

The wall temperature of the entire powertrain system is measured using the Testo 835-T2 infrared thermometer and the result can be seen real-time. Table III shows the data result of the wall temperature gauging. 
TABLE III Data of the Powertrain System Wall Temperature

\begin{tabular}{|l|l|l|}
\hline Part & Material & Wall temperature \\
\hline Bellmouth & Aluminum & $303 \mathrm{~K}$ \\
\hline Throttle body & Aluminum & $302 \mathrm{~K}$ \\
\hline Restrictor & PVA & $304 \mathrm{~K}$ \\
\hline Plenum & PVA & $304 \mathrm{~K}$ \\
\hline Intake manifold & Aluminum & $310 \mathrm{~K}$ \\
\hline Intake port & Aluminum & $341 \mathrm{~K}$ \\
\hline Engine block & Aluminum & $341 \mathrm{~K}$ \\
\hline Exhaust port & Aluminum & $368 \mathrm{~K}$ \\
\hline Exhaust adaptor & Stainless steel & $530 \mathrm{~K}$ \\
\hline Header 1 & Monel & $534 \mathrm{~K}$ \\
\hline Header 2 & Monel & $532 \mathrm{~K}$ \\
\hline Header 3 & Monel & $435 \mathrm{~K}$ \\
\hline Muffler pipe & Stainless steel & $397 \mathrm{~K}$ \\
\hline Muffler & Aluminum & $327 \mathrm{~K}$ \\
\hline Tail pipe & Stainless steel & $307 \mathrm{~K}$ \\
\hline
\end{tabular}

Apart from the data above, the data of engine condition when it runs in the competition is also required. The said data is attained from the MoTeC M400 ECU logging.

\section{B. Ricardo WAVE Modelling}

After all data is compiled, the model for Ricardo WAVE simulation is ready to be created using WaveBuild sub-software. Fig. 3 shows the powertrain system simulation model on Bimasakti racing car.

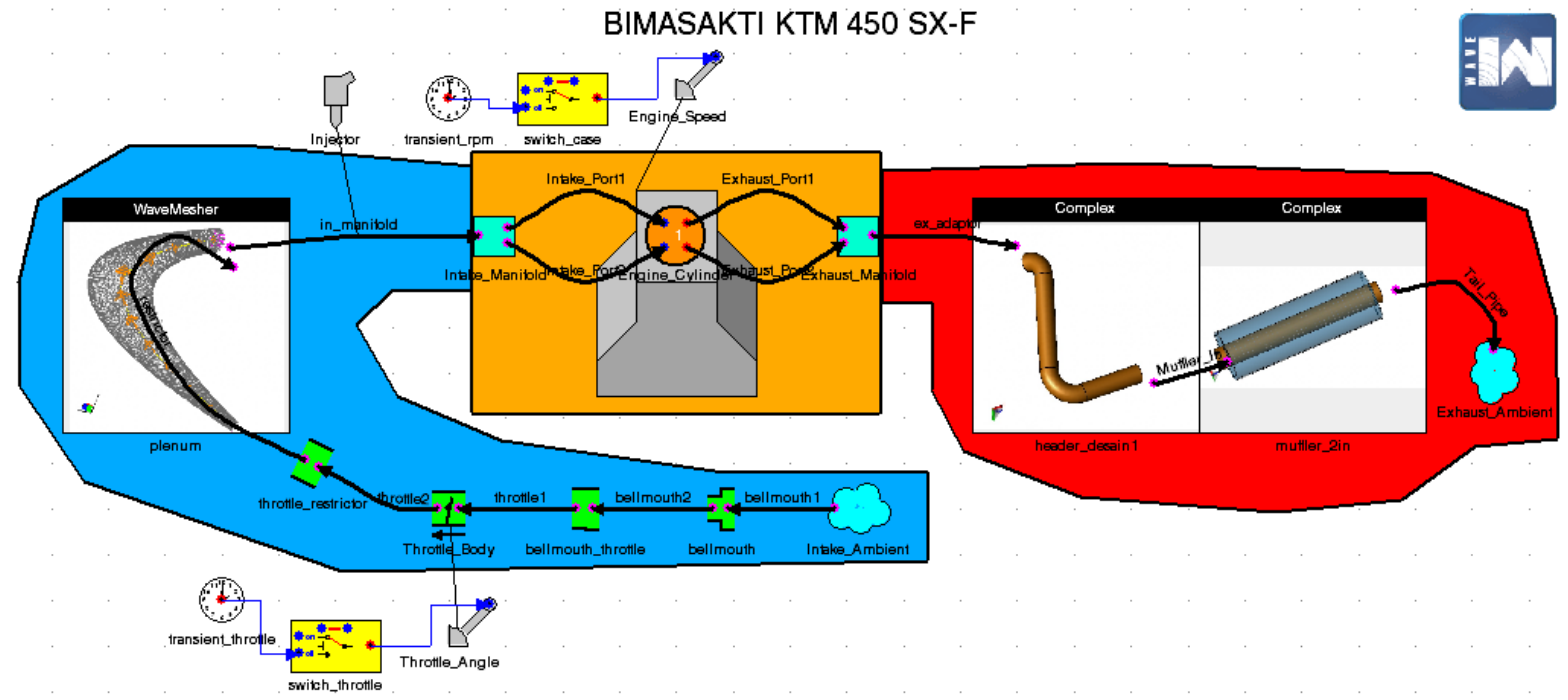

Fig. 3. Ricardo WAVE simulation model

\section{Running the Simulation}

Once the Ricardo WAVE simulation model completed, modification to the exhaust system header is performed. Press the run input check symbol in the toolbar to ensure that the required data is complete, and then run the simulation. Header is varied to the dimensions of length and diameter, and after acquiring the best measurement, the header would be developed with the addition of expansion chamber, stepped pipe and diffuser.

\section{III.RESULTS AND DISCUSSION}

In this study, several variations of the exhaust system header geometry are made to get the best header design to optimize power and torque of the KTM 450 SX-F engine. The variations and the results of the simulation are as follows: 


\section{A. Pipe Header Variations in Length and Diameter}

The first header geometry variation in the simulation is the difference in length and diameter. There are 9 designs compared, along with header Design 1 which is the original design of the Bimasakti car. The specification of each design showing the average power and torque WAVE simulation results in engine rotation speed range of 3,000 to 10,000 rpm can be seen in Table IV.

TABLE IV Design 1 - 10 Specifications and Simulation Results

\begin{tabular}{|c|c|c|c|c|}
\hline Design Number & Diameter (mm) & Length (mm) & Power (HP) & Torque (Nm) \\
\hline 1 & 45.50 & 635 & 27.99 & 28.54 \\
\hline 2 & 36.10 & 600 & 26.46 & 27.59 \\
\hline 3 & 36.10 & 800 & 26.00 & 27.47 \\
\hline 4 & 36.10 & 1,000 & 25.13 & 26.96 \\
\hline 5 & 42.45 & 600 & 27.40 & 28.20 \\
\hline 6 & 42.45 & 800 & 27.47 & 28.76 \\
\hline 7 & 42.45 & 1,000 & 26.76 & 28.30 \\
\hline 8 & 48.80 & 600 & 27.73 & 28.20 \\
\hline 9 & 48.80 & 800 & 27.89 & 28.93 \\
\hline 10 & 48.80 & 1,000 & 27.30 & 28.80 \\
\hline
\end{tabular}

Design simulation result graph 1 to 10 can be seen in Fig. 4 below.

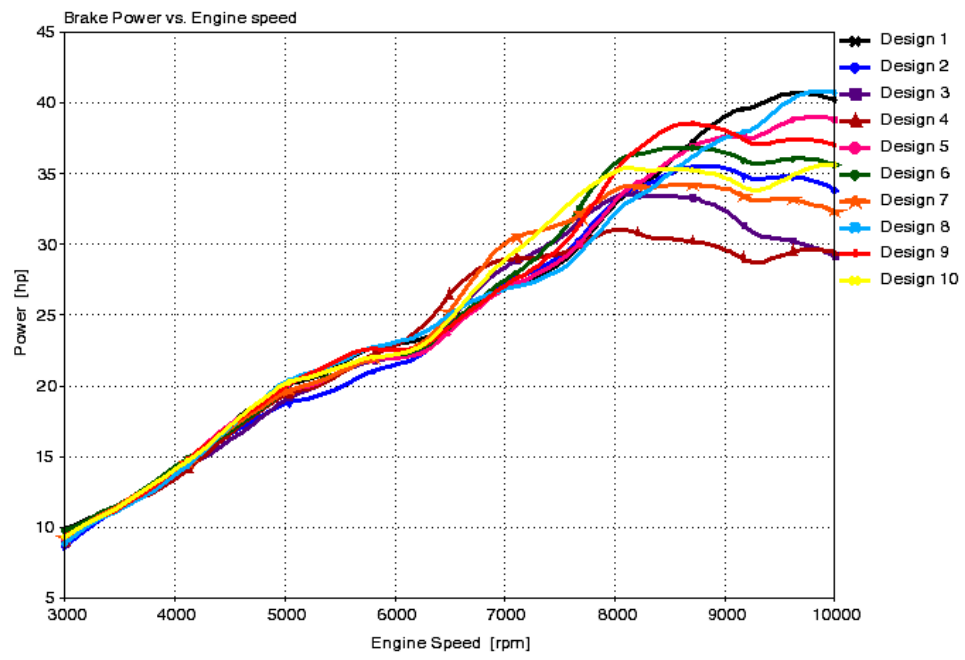

(a)

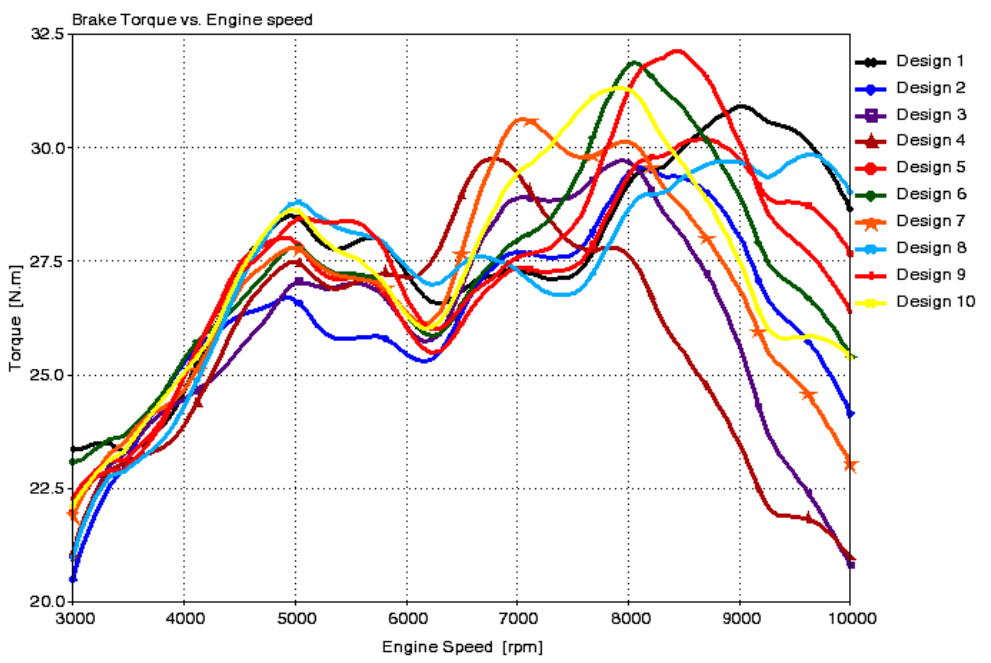

(b)

Fig. 4. Design 1 - 10 simulation result graphs, (a) Power, and (b) Torque 
From Table IV, it is known that the largest average value of power is in Design 1, while the average value of torque is biggest in Design 9. However, when the average value is summed, Design 9 has the largest total value and thus this design would be developed with extra expansion chamber, stepped pipe and diffuser geometries.

\section{B. Expansion Chamber Variation}

Expansion chamber with a diameter of $61.50 \mathrm{~mm}$ is added to header Design 9. Four variations of length and position of the expansion chamber are to be simulated in the header at WAVE. Table $\mathrm{V}$ shows the design specifications showing the power and torque simulation results.

TABLE V Design 11 - 14 Specifications and Simulation Results

\begin{tabular}{|c|c|c|c|c|}
\hline Design Number & Length (mm) & Position (mm) & Power (HP) & Torque (Nm) \\
\hline 11 & 50 & 245 & 27.99 & 28.54 \\
\hline 12 & 50 & 490 & 26.46 & 27.59 \\
\hline 13 & 100 & 245 & 26.00 & 27.47 \\
\hline 14 & 100 & 490 & 25.13 & 26.96 \\
\hline
\end{tabular}

Design simulation result graph 11 to 14 as compared to Design 9 can be seen in Fig. 5 below.

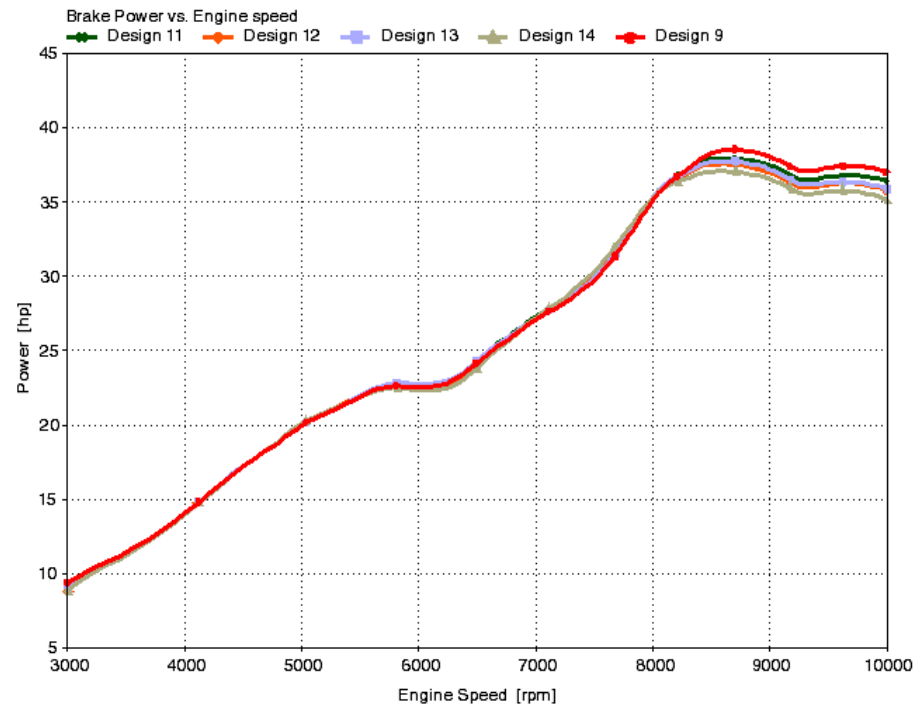

(a)

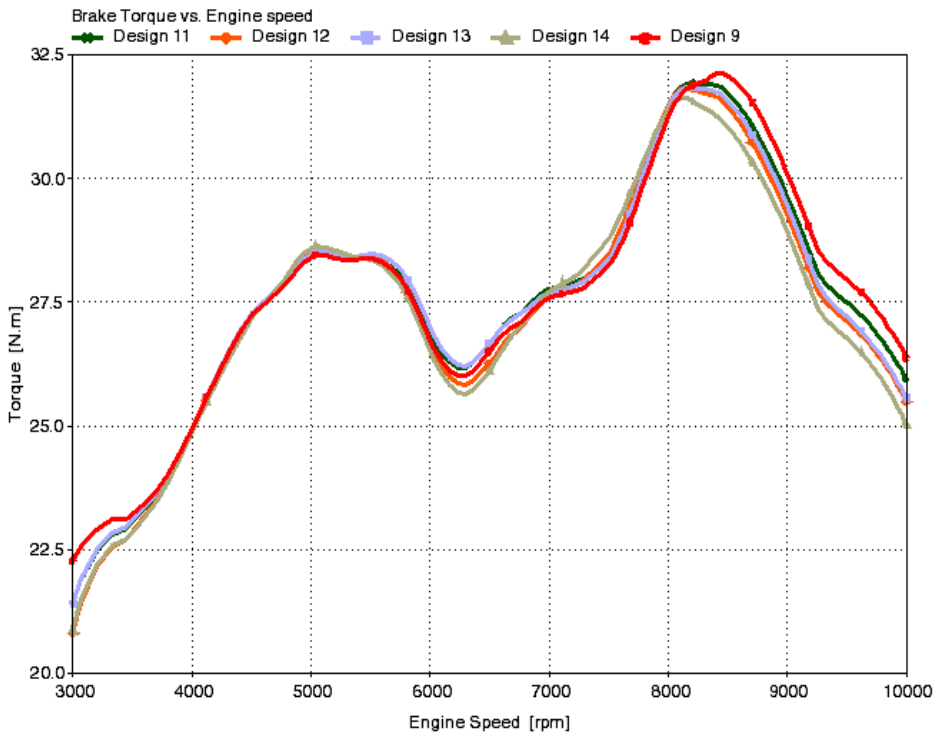

(b)

Fig. 5. Design $11-14$ simulation result graphs, (a) Power, and (b) Torque 
It is seen from Table $\mathrm{V}$ that Design 11 has a largest total average value of power and torque, but still lower than those in Design 9. From Fig. 5 it is known that the addition of the expansion chamber actually reduces the value of power and torque at high engine rotation speed.

\section{Expansion Stepped Pipe Variation}

The second variation is the addition of multi-step pipe. The pipe at the end of the varied header position is enlarged to $61.50 \mathrm{~mm}$. Table VI shows a list of design with the average value of power and torque.

TABLE VI Design 15 - 16 Specifications and Simulation Results

\begin{tabular}{|l|l|l|l|}
\hline Design Number & Position (mm) & Power (HP) & Torque (Nm) \\
\hline 15 & 245 & 28.10 & 28.76 \\
\hline 16 & 490 & 28.40 & 28.80 \\
\hline
\end{tabular}

Design simulation result graph 15 and 16 compared to Design 9 can be seen in Fig. 6 below .

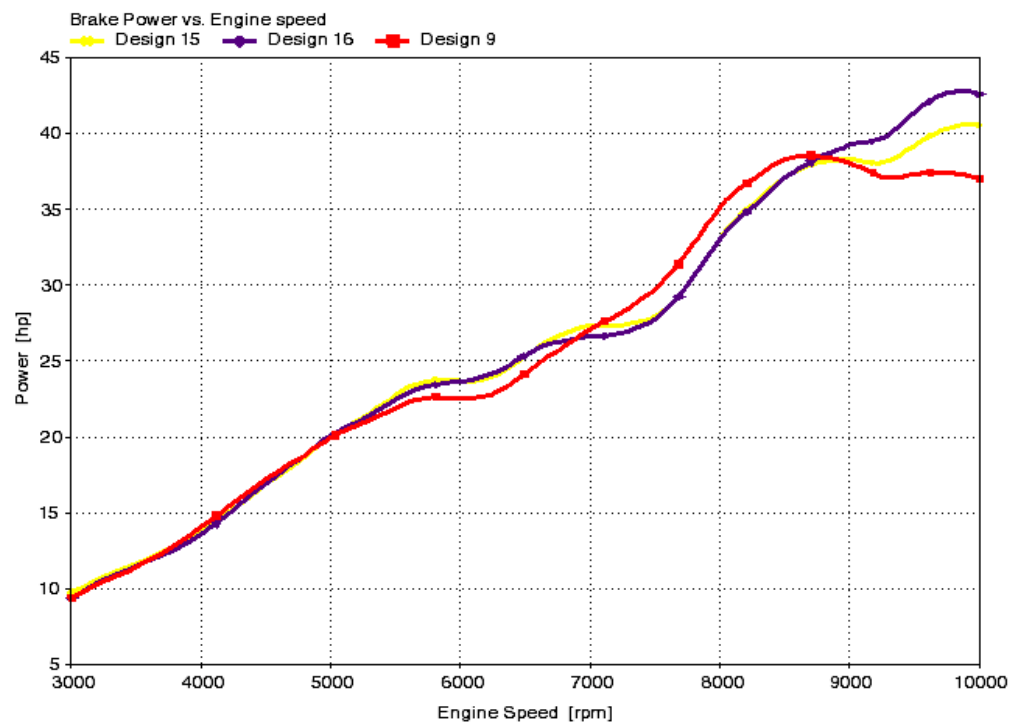

(a)

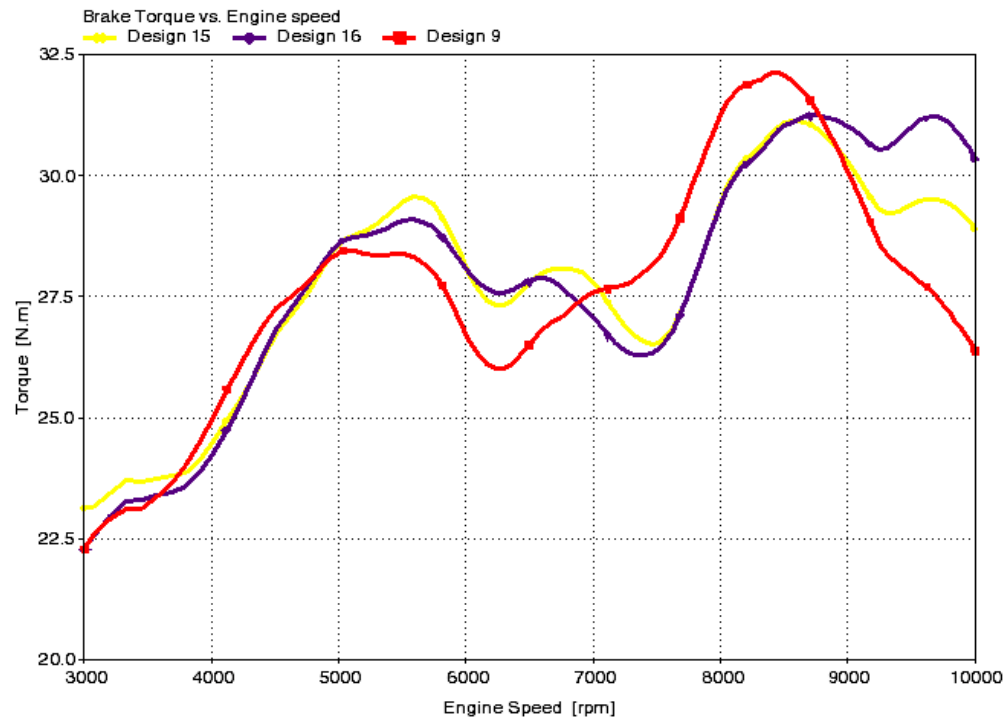

(b)

Fig. 6. Design 15 - 16 simulation result graphs, (a) Power, and (b) Torque

In Table VI it is shown that Design 16 has a largest total average value of power and torque. Fig. 6 shows that the design with the addition of stepped pipe can increase the value of power and torque at both low and high engine rotation speed. Meanwhile, Design 9 would have a good value of power and torque at medium engine rotation speed. 


\section{Diffuser Variation}

The third form of variations is the addition of a diffuser at the end of the header. This form is varied to 3 lengths and 2 angles of diffuser, resulting in 6 designs as shown in Table VII with an average value of power and torque.

TABLE VII Design 1 - 10 Specifications and Simulation Results

\begin{tabular}{|c|c|c|c|c|}
\hline Design Number & Length (mm) & Angle (mm) & Power (HP) & Torque (Nm) \\
\hline 17 & 75 & 5 & 28.49 & 29.19 \\
\hline 18 & 150 & 5 & 28.71 & 29.16 \\
\hline 19 & 75 & 10 & 28.66 & 29.04 \\
\hline 20 & 150 & 10 & 28.89 & 28.99 \\
\hline 21 & 75 & 14 & 28.84 & 29.06 \\
\hline 22 & 150 & 14 & 29.03 & 29.00 \\
\hline
\end{tabular}

Design simulation result graph 17 to 22 compared to Design 9 can be seen in Fig. 7 below.

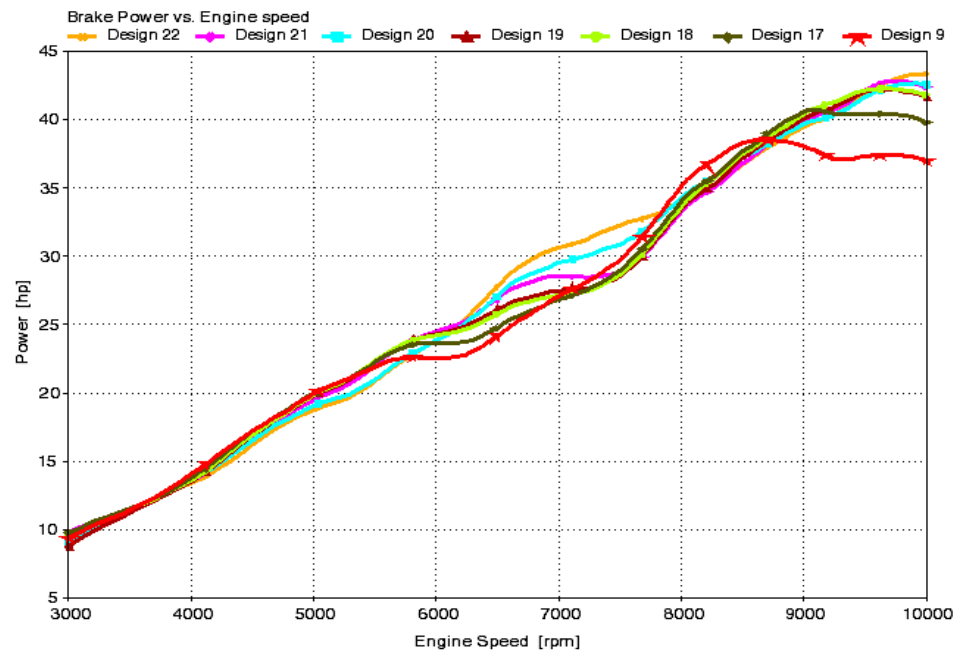

(a)

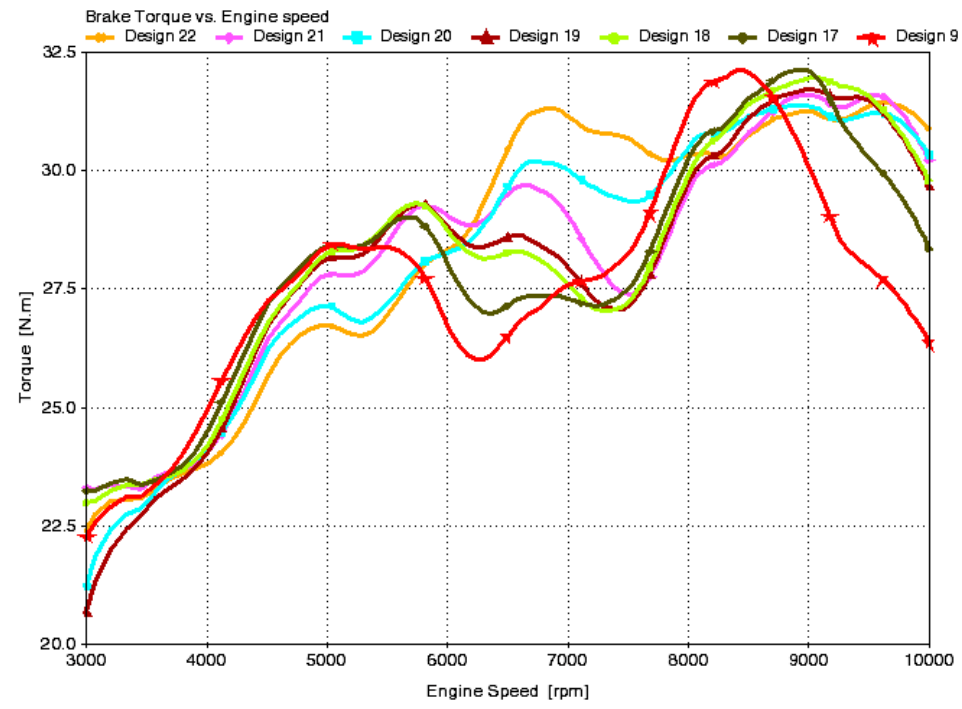

(b)

Fig. 7. Design 17 - 22 simulation result graphs, (a) Power, and (b) Torque

By varying the length and angle of the diffuser, it is known that Design 22 is the design that has a largest total average value of the power and torque according to the data in Table VII. Meanwhile, Fig. 7 shows the value of power and torque at low and high engine rotation speed can be increased by the addition of a diffuser, but in the medium engine rotation speed is to be superior Design 9 without diffuser. 


\section{E. Selection of Best Design}

After 22 designs are simulated in Ricardo WAVE, it is known that the best design for each variation is Design 9 for variations in the geometry in length and diameter of the pipe header, Design 11 for variations in the geometry of the expansion chamber, Design 16 for variations in the geometry of the stepped pipe, and Design 22 for variations in geometry diffuser. Fig. 8 shows a graph of the value of power and torque in Design 1, 9, 11, 16 and 22.

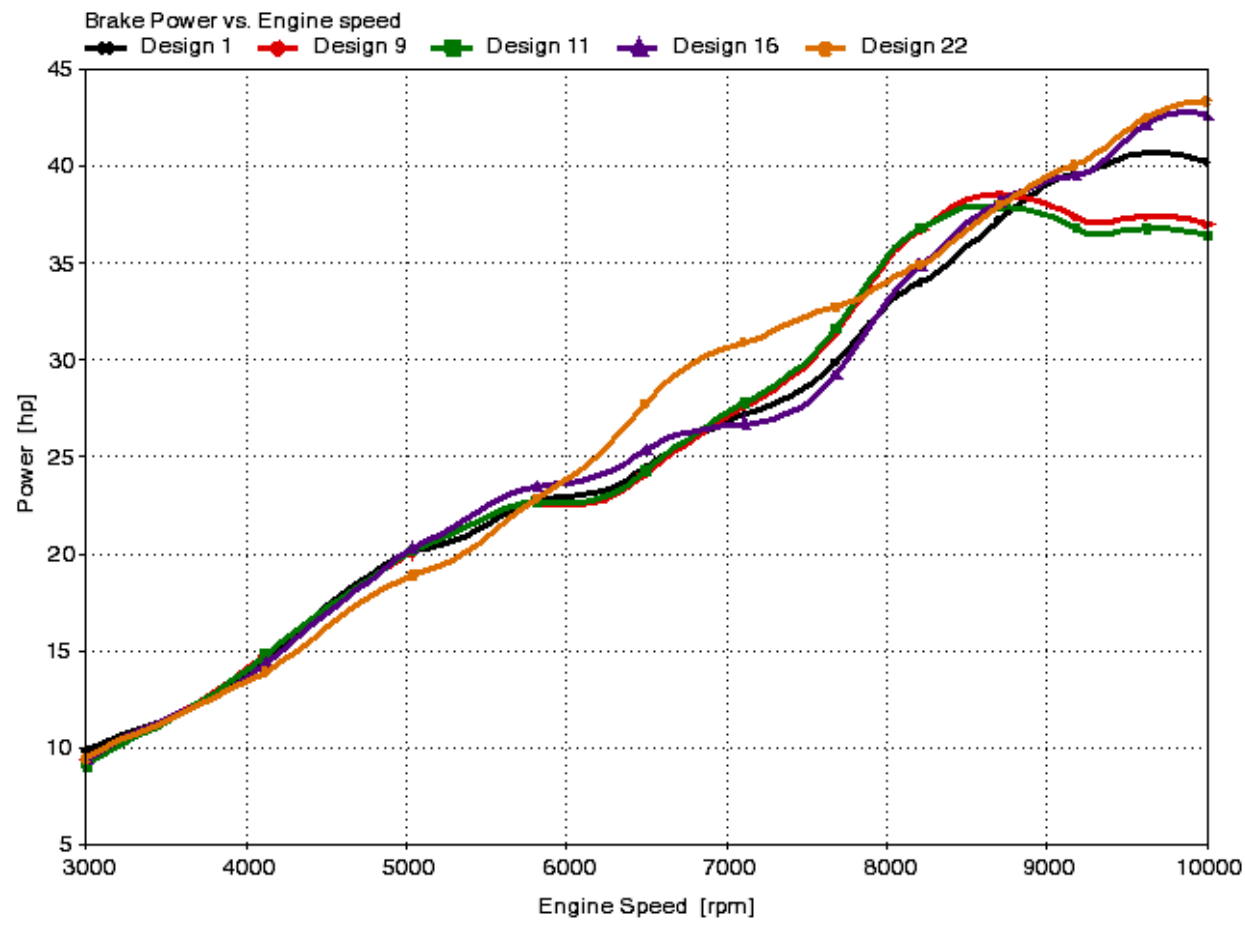

(a)

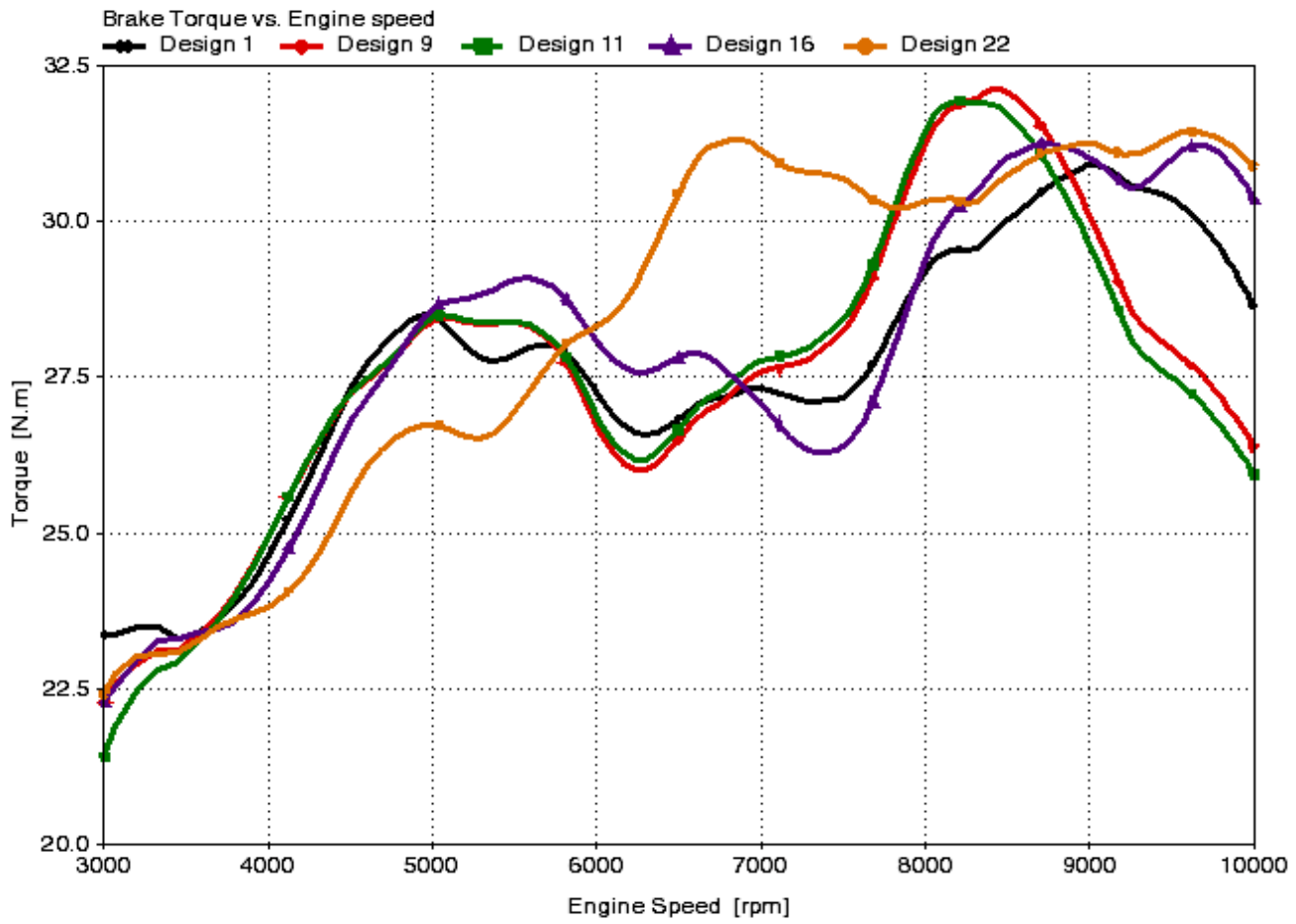

(b)

Fig. 8. Design 1, 9, 11, 16 and 22 simulation result graphs, (a) Power, and (b) Torque

Readings of power and torque graph of the engine rotation speed can be seen in Table VIII. 
TABLE VIII Design 1, 9, 11, 16 and 22 Power and Torque Values on Engine Speed Range

\begin{tabular}{|c|c|c|c|c|c|c|}
\hline \multirow{2}{*}{$\begin{array}{l}\text { Engine } \\
\text { Speed Range }\end{array}$} & \multirow[b]{2}{*}{ Parameter } & \multicolumn{5}{|c|}{ HEADER DESIGN VALUE } \\
\hline & & $\begin{array}{c}\text { Original } \\
\text { Design (1) }\end{array}$ & $\begin{array}{c}\text { Length and } \\
\text { Diameter (9) }\end{array}$ & $\begin{array}{c}\text { Expansion } \\
\text { Chamber (11) }\end{array}$ & $\begin{array}{l}\text { Stepped } \\
\text { Pipe (16) }\end{array}$ & $\begin{array}{c}\text { Diffuser } \\
(22)\end{array}$ \\
\hline \multirow{2}{*}{$3,000-4,000$} & Power & 13.8 & 13.9 & 14.0 & 13.5 & 13.3 \\
\hline & Torque & 24.6 & 24.9 & 24.9 & 24.2 & 23.8 \\
\hline \multirow{2}{*}{$4,000-5,000$} & Power & 20.0 & 19.9 & 20.0 & 20.1 & 18.7 \\
\hline & Torque & 28.5 & 28.3 & 28.4 & 28.5 & 26.7 \\
\hline \multirow{2}{*}{$5,000-6,000$} & Power & 22.9 & 22.6 & 22.6 & 23.6 & 23.8 \\
\hline & Torque & 28.4 & 28.4 & 28.5 & 29.1 & 28.3 \\
\hline \multirow{2}{*}{$6,000-7,000$} & Power & 26.8 & 27.0 & 27.3 & 26.6 & 30.6 \\
\hline & Torque & 27.3 & 27.5 & 27.7 & 28.0 & 31.3 \\
\hline \multirow{2}{*}{$7,000-8,000$} & Power & 32.7 & 35.1 & 35.3 & 33.0 & 34.0 \\
\hline & Torque & 29.2 & 31.2 & 31.4 & 29.4 & 30.3 \\
\hline \multirow{2}{*}{$8,000-9,000$} & Power & 39.0 & 38.6 & 38.1 & 39.2 & 39.5 \\
\hline & Torque & 30.9 & 32.1 & 32.0 & 31.2 & 31.2 \\
\hline \multirow{2}{*}{$\begin{array}{l}9,000- \\
10,000\end{array}$} & Power & 40.7 & 38.1 & 37.6 & 42.8 & 43.3 \\
\hline & Torque & 30.9 & 36.1 & 29.7 & 31.2 & 31.4 \\
\hline \multirow{2}{*}{ Total Value } & Power & 195.9 & 195.2 & 194.9 & 198.8 & 203.2 \\
\hline & Torque & 199.8 & 208.5 & 202.6 & 201.6 & 203.0 \\
\hline \multirow{2}{*}{$\begin{array}{l}\text { Average } \\
\text { Value }\end{array}$} & Power & 27.99 & 27.89 & 27.84 & 28.40 & 29.03 \\
\hline & Torque & 28.54 & 29.79 & 28.94 & 28.80 & 29.00 \\
\hline \multicolumn{2}{|l|}{ Final Value } & 395.7 & 403.7 & 397.5 & 400.4 & 406.2 \\
\hline
\end{tabular}

In Table VIII it can be seen that the value of power and torque for the different design variation with the engine rotation speed range of 3,000 rpm to $10,000 \mathrm{rpm}$. On the table shows that the design with the addition of expansion chamber (Design 11) has a higher power and torque value than Design 9 at engine rotation speed of $3,000-8,000 \mathrm{rpm}$, then becomes lower at 8,000 - 10,000 rpm. In the design with the addition of stepped pipe (Design 16), its value is higher than Design 9 at engine rotation speed of 4,000-6,000 rpm, then becomes lower at 6,000-8,000 rpm, and rises again at 8,000-10,000 rpm. Meanwhile, the torque values of Design 16 are superior compared to Design 9 at engine rotation speed of 4,000-7,000 rpm, then becomes lower at 7,00010,000 rpm. Lastly, with the additional diffuser design (Design 22), the power is lower than Design 9 on the engine rotation speed of 3,000-5,000 rpm, and then excels at 5,000-10,000 rpm. Meanwhile, the torque value of Design 22 is lower at 3,000-6,000 rpm, and excels at 6,000-10,000 rpm.

\section{IV.CONCLUSION}

In this study, it can be concluded that the use of Ricardo WAVE software for designing the header exhaust system is very efficient because it can perform simulation with many variations, at no cost. Then we knew that the addition of the expansion chamber can reduce the value of power and torque, while the addition of stepped pipe and diffuser on a header exhaust system can increase the value of power and torque. The best design that can be used for KTM 45 SX-F engine in the Bimasakti Formula SAE race car is Design 22, i.e. the design with a pipe diameter of $48.80 \mathrm{~mm}$, pipe length of $800 \mathrm{~mm}$, with the addition of a diffuser with $14^{\circ}$ angle and $150 \mathrm{~mm}$ of length.

\section{ACKNOWLEDGMENT}

The authors hope that this research can help Bimasakti FSAE UGM team in competing, so that the team can continue to develop researches for the advancement of automotive technology. Finally, the authors would like to acknowledge the Faculty of Engineering, Universitas Gadjah Mada for their support to this research through an international publication preparation grant program.

\section{REFERENCES}

[1] SAE International. (2016) 2017-18 Formula SAE® Rules. [Online]. Available: http://students.sae.org/cds/formulaseries/rules/

[2] G. P. Blair, Design and Simulation of Four-Stroke Engines, Warrendale, United States of America: Society of Automotive Engineers Inc., 1999.

[3] D. Deshmukh, R. Kumar, M. Garg, M. J. Nayeem, and V. Lakshminarasimhan, “Optimization of Gas Exchange Process on a Single Cylinder Small 4-Stroke Engine by Intake and Exhaust Tuning: Experimentation and Simulation”, SAE Transaction, American Technical Publishers Ltd., vol. 113, 2004.

[4] C. J. Shih, Y. Chi-Yan, and C. Ting-Hao, "Experimental Optimization and Analysis of Intake and Exhaust Pipeline for Small Engine Motorcycle”, Journal of Applied Science and Engineering, vol. 15, pp. 21-30, 2012. 
[5] S. D. Pangavhane, A. B. Ubale, V. A. Tandon, and D. R. Pangavhane, "Experimental and CFD Analysis of a Perforated Inner Pipe Muffler for the Prediction of Backpressure”, International Journal of Engineering and Technology (IJET), vol. 5, pp. 3940-3950, Nov. 2013.

[6] A. A. Patil, L. G. Navale, and V. S. Patil, "Experimental Investigation and Analysis of Single Cylinder Four Stroke C.I. Engine Exhaust System”, International Journal of Energy and Power (IJEP), vol. 3, pp. 1-6, Feb. 2014.

[7] A. R. Manickam, K. Rajan, N. Manoharan, and K. R. S. Kumar, "Reduction of Exhaust Emissions on a Biodiesel fueled Diesel Engine with the Effect of Oxygenated Additives”, International Journal of Engineering and Technology (IJET), vol. 6, pp. 2406-2411, Nov. 2014.

[8] J. M. Middelberg, T. J. Barber, S. S. Leong, K. P. Byrne, and E. Leonardi, “Computational Fluid Dynamics Analysis of The Acoustic Performance of Various Simple Expansion Chamber Mufflers”, Proceedings of Acoustics, The University of New South Wales, Gold Coast, Australia, Nov. 2004.

[9] M. Hahlin, “Single Cylinder ICE Exhaust Optimization”, M. Sc. Thesis, Lulea University of Technology, Lulea, Sweden, 2013.

[10] H. Han-chi, H. Huang, and Y. Bai, "Optimization of Intake and Exhaust System for FSAE Car Based on Orthogonal Array Testing”, International Journal of Engineering and Technology (IJET), vol. 2, pp. 392-396, Mar. 2012.

[11] M. Ales, M. Rafael, T. Mitch, V. Leon, "Cal Poly Formula SAE Engine Development”, California Polytechnic State University, San Luis Obispo, June 2010.

[12] M. R. Plank, "Engine Optimization and Performance Characteristics for a Formula SAE Race Car”, B. Eng. Thesis, University of Southern Queensland, Springfield, Australia, 2005.

[13] A. I. McLeod, “An Investigation into Formula SAE Performance Exhaust Design and Analysis”, B. Eng. Thesis, University of New South Wales at the Australian Defense Force Academy, Campbell, Australia, 2011.

\section{AUTHOR PROFILE}

Fauzun is an Assistant Professor and Secretary of Mechanical and Industrial Engineering Department, Faculty of Engineering, Universitas Gadjah Mada. His research interest areas are heat and mass transfer, and energy conversion.

Arif Kurniawan is an undergraduate student at the of Mechanical and Industrial Engineering Department, Faculty of Engineering, Universitas Gadjah Mada. He is a head of engine and electrical division in the fifth generation of Bimasakti Formula SAE UGM team. His interest is in the field of energy conversion and automotive technology. 